\title{
Effect of Molecular Sizes of Chondroitin Sulfate on Interaction with L-Selectin
}

\author{
Naoko Igarashi, ${ }^{1}$ Atsuko Takeguchi, ${ }^{1}$ Shinobu Sakai, ${ }^{2}$ Hiroshi Akiyama, ${ }^{2}$ \\ Kyohei Higashi, ${ }^{1}$ and Toshihiko Toida ${ }^{1}$ \\ ${ }^{1}$ Graduate School of Pharmaceutical Sciences, Chiba University, 1-8-1 Inohana, Chuo, Chiba 260-8675, Japan \\ ${ }^{2}$ National Institute of Health Sciences, 1-18-1 Kamiyoga, Setagaya, Tokyo 158-8501, Japan \\ Correspondence should be addressed to Toshihiko Toida; toida@faculty.chiba-u.jp
}

Received 11 March 2013; Accepted 13 April 2013

Academic Editor: R. J. Linhardt

Copyright (C) 2013 Naoko Igarashi et al. This is an open access article distributed under the Creative Commons Attribution License, which permits unrestricted use, distribution, and reproduction in any medium, provided the original work is properly cited.

\begin{abstract}
Chondroitin sulfate (CS) is a glycosaminoglycan (GAG) side chain of proteoglycans (PGs) which are widely distributed in the extracellular matrix and at cell surface. CS shows a highly structural diversity in not only molecular weight (MW) but sulfonation pattern. CS has been reported to exert anti-inflammatory activity by having effects on cytokine production by helper T cells. In this study, we focused on the structures of CS chains, especially MW of CS, and investigated effect of the different MW of CS on binding affinity with L-selectin and cytokine production by murine splenocytes. Firstly, we fractionated CS by employing gel filtration chromatography and obtained several CS fractions with different MW. Then the interaction between fractionated CS and L-selectin was analyzed by surface plasmon resonance (SPR). Finally, the influence of MW of CS on cytokine production by murine splenocytes was investigated in vitro. The results showed that interferon-gamma production was significantly increased by mouse splenocytes cocultivated with CS. On the contrary, CS inhibited interleukin 5 production by murine splenocytes depending on MW of the cocultivated CS. These results strongly indicate the existence of the optimal molecular size for an anti-inflammatory effect of CS through cytokine production by murine splenocytes.
\end{abstract}

\section{Introduction}

Chondroitin sulfate (CS) belongs to a family of glycosaminoglycans (GAG), which is a linear, sulfonated polysaccharide, such as heparin (HP), heparan sulfate (HS), and dermatan sulfate (DS). CS is composed of a repeating disaccharide unit, [-4) GlcA ( $\beta 1-3)$ GalNAc $(\beta 1-]_{n}$, where GlcA is glucuronate and GalNAc is $N$-acetylgalactosamine [1]. CS chains show structural diversity because sulfonate groups can be bound to variety positions of the disaccharide units, and its molecular weight $(\mathrm{MW})$ is also highly variable due to different numbers of the disaccharide unit [2-4]. On the other hand, it is well known that CS and other GAGs form conjugates with the specific proteins called proteoglycans (PGs) and PGs are ubiquitously distributed in not only extracellular matrix but also on cell surface in animal tissues. PGs are thought to be participating in cell-cell communications such as a cell adhesion and signalling events via proteins, especially; HS chains can control a signalling by interacting with cell growth factors and HP has been widely used as an anticoagulant agent [5-7]. Correspondingly, CS has also a similar function and it has been reported that CS contributes to various bioactivities, for example, development of central nervous system, wound healing, and signalling via cell growth factors [8-11]. Furthermore, there have been a large number of reports on anti-inflammatory activity of CS [12-14]. Kawashima et al. revealed that versican, a large CSPG, in the kidney reacts with leukocyte adhesion molecule, L-selectin, by interacting with CS chains, and the binding affinity of CS against L-selectin differs with the sulfonate positions of CS chains [15-18].

Generally, immune response is classified into two types, innate and adaptive immunity systems. Innate immunity system works as the first defense against invading pathogens and then differentiated lymphocytes, for example, killer and 
helper $\mathrm{T}$ cells, and antibody-secreting cells, play a role in antigen-specific immune response. The encounter with antigen can induce the differentiation of helper $\mathrm{T}$ cells to at least two functional classes of cell types, Th1 cells and Th2 cells, which secrete specific cytokines such as interferon-gamme (IFN- $\gamma$ ) or interluekin-4 (IL-4), respectively $[19,20]$. Once an undifferentiated $\mathrm{T}$ cell called naive $\mathrm{T}$ cell begins to develop along with one pathway, it tends to become progressively polarized in that direction. This polarization is regulated by cytokines which Th1 cell or Th2 cell secreted. We have already reported that CS upregulates the antigen-specific Th1 immune response on murine splenocytes sensitized with ovalbumin (OVA) in vitro, and that CS suppresses the antigen-specific IgE responses [12]. Moreover, we showed that the content, position, and number of $\mathrm{O}$-sulfo groups in CS are of importance in immunological activity in vitro [13]. Furthermore, Th1-promoted and Th2-inhibitory activity of CS on murine splenocytes could be associated with binding to L-selectin [13]. These findings might have been clarified the contribution of $O$-sulfo groups to immunological activity of CS via L-selectin.

In this study, we have further investigated the effect of MW of CS on the immune response, especially cytokine production by murine splenocytes sensitized with OVA, in vitro.

\section{Materials and Methods}

2.1. Chemicals. CS-A, prepared from bovine tracheal cartilage and having an average molecular weight of $15 \mathrm{kDa}$, was a gift from Shin-Nippon Yakugyo Co. (Tokyo, Japan). CS-C was kindly provided by San-Ei Gen FFI Co. (Osaka, Japan). CS-A from whale cartilage having an average molecule weight of $21 \mathrm{kDa}$ was purchased from Seikagaku Kogyo Co. (Tokyo, Japan). CS-B, CS-D, CS-E, unsaturated disaccharides, and chondroitinase $\mathrm{ABC}$ were also purchased from Seikagaku Kogyo Co. (Tokyo, Japan).

2.2. Preparation of Fractionated CS. Solution of CS $(10 \mathrm{mg} / \mathrm{mL})$ dissolved in purified water was fractionated by using gel filtration column $(100 \mathrm{~cm} \times 4.6 \mathrm{~cm}$ i.d. $)$ filled with Sephadex G-100 superfine (GE Healthcare, UK). The mobile phase consisted of $0.2 \mathrm{M} \mathrm{NaCl}$. One hundred drops of eluate solution were collected in each glass vial. Then fractions were detected by UV absorbance at $204 \mathrm{~nm}$. Twenty fractions were collected in one and concentrated into onetwentieth by evaporation followed by desalting on a HiTrap Desalting Column.

The separation of desalted fractionated CS was confirmed by using gradient polyacrylamide gel electrophoresis (PAGE). Ten $\mu \mathrm{g}$ of fractionated CS was dissolved in $50 \mu \mathrm{L}$ of $50 \%$ sucrose solution containing $0.01 \%$ bromophenol blue and loaded on a gradient PAGE gel (PAGEL NPG-1020 L, 10$20 \%, 90 \mathrm{~mm} \times 78 \mathrm{~mm} \times 1 \mathrm{~mm}$ gel thickness, ATTO Co. Ltd., Tokyo). The electrophoresis was conducted by using a $0.2 \mathrm{M}$ tris-1.2 M glycine mixture as a buffer under $100 \mathrm{~V}$ for $60 \mathrm{~min}$.

The molecular weight of each fractionated CS was determined with a high-performance gel chromatography.
The average molecular weight of fractionated CS was calculated from standard curve prepared by using molecular weight known CS sample. The structures of fractionated CS were confirmed by ${ }^{1} \mathrm{H}$ NMR $(500 \mathrm{MHz})$ [21].

2.3. Disaccharide and Composition Analyses of Fractionated CS. The determination of unsaturated disaccharides $(\triangle \mathrm{Di}$ 0S, $\Delta$ Di-4S, $\Delta$ Di-6S, $\Delta$ Di-diSE, $\Delta \mathrm{Di}$-diSB, $\Delta \mathrm{Di}$-diSD, and $\Delta$ Di-triS), prepared from the fractionated CS, was performed on the lyase-digested samples using high-performance liquid chromatography $[22,23]$. Briefly, chondroitinase digestion was performed using tris-acetate buffer $(5 \mu \mathrm{L}, 0.2 \mathrm{M}, \mathrm{pH} 8.0)$ and $10 \mu \mathrm{L}$ of an aqueous solution containing chondroitinase $\mathrm{ABC}(50 \mathrm{mIU})$ and chondroitinase ACII $(50 \mathrm{mIU})$ were added to a $20 \mu \mathrm{L}$ portion of the sample solution and incubated at $37^{\circ} \mathrm{C}$ for $3 \mathrm{~h}$. An $8 \mu \mathrm{L}$ portion of this mixture was analyzed by high-performance liquid chromatography.

2.4. Estimation of the Molecular Weight of CS. The molecular weights of the fractionated CS were estimated by an HPSEC system that consisted of a Hitachi L-6000 pump (Hitachi Co., Japan), Rheodyne 7725i loop injector (IDEX Health \& Science, USA), and a YRD-880 refractive index detector (Shimamura Instruments Co., Japan). The column used was an Asahipak 510 HQ column $(7.6 \mathrm{~mm}$, i.d. $\times 300 \mathrm{~mm}$ ) (Shodex, Showa Denko Co. Ltd., Tokyo) and eluted with $10 \mathrm{mM}$ $\mathrm{NH}_{4} \mathrm{HCO}_{3}$ at a flow rate of $0.3 \mathrm{~mL} / \mathrm{min}$. The molecular weight standards of CS $(15.4,22.4,31.0$, and $50.0 \mathrm{kDa}$ from shark cartilage) were kindly gifted from Seikagaku Co. Ltd. (Tokyo).

\subsection{Kinetic Analysis Using BIAcore between CS and L-} Selectin. Recombinant mouse L-selectin was purchased from Sigma-Aldrich Japan (Tokyo, Japan). The interaction between fractionated CS and L-selectin was analyzed by a BIAcore biosensor (GE healthcare, Tokyo). All experiments were performed at $25^{\circ} \mathrm{C}$. The running buffer which was provided from the manufacture consisted of $10 \mathrm{mM}$ HEPES $\mathrm{pH}$ 7.4, $0.15 \mathrm{M} \mathrm{NaCl}, 3 \mathrm{mM}$ EDTA, and $0.005 \%$ Surfactant P20. First, L-selectin was covalently immobilized on the CM5 sensor chip covered with carboxymethyl dextran via its primary amine groups using an amino coupling kit according to the instructions provided from the manufacturer. The remaining activated groups were blocked with $1 \mathrm{M}$ ethanolamine. One control cell was prepared by blocking with ethanolamine. CS samples were dissolved in $50 \mathrm{mM}$ tris- $\mathrm{HCl}$ buffer. The different concentrations of the each fractionated CS were injected at $20 \mu \mathrm{L} / \mathrm{min}$. The sensor chip surface was regenerated with $1 \mathrm{M} \mathrm{NaCl}$. Affinity kinetic parameters were determined with BIAevaluation 3.0 software using a single-site binding model.

2.6. Animals. Inbred specific pathogen-free $B A L B / c$ mice (female, 6 weeks of age) were purchased from Nihon SLC Inc. (Shizuoka, Japan). The mice were maintained in a temperature $\left(25^{\circ} \mathrm{C}\right)$, humidity $(55 \%)$, and light-controlled environment with free access to Rodent diet EQ (Nihon SLC Inc., Shizuoka, Japan) and water. They were acclimatized for at least 1 week before the start of study. 


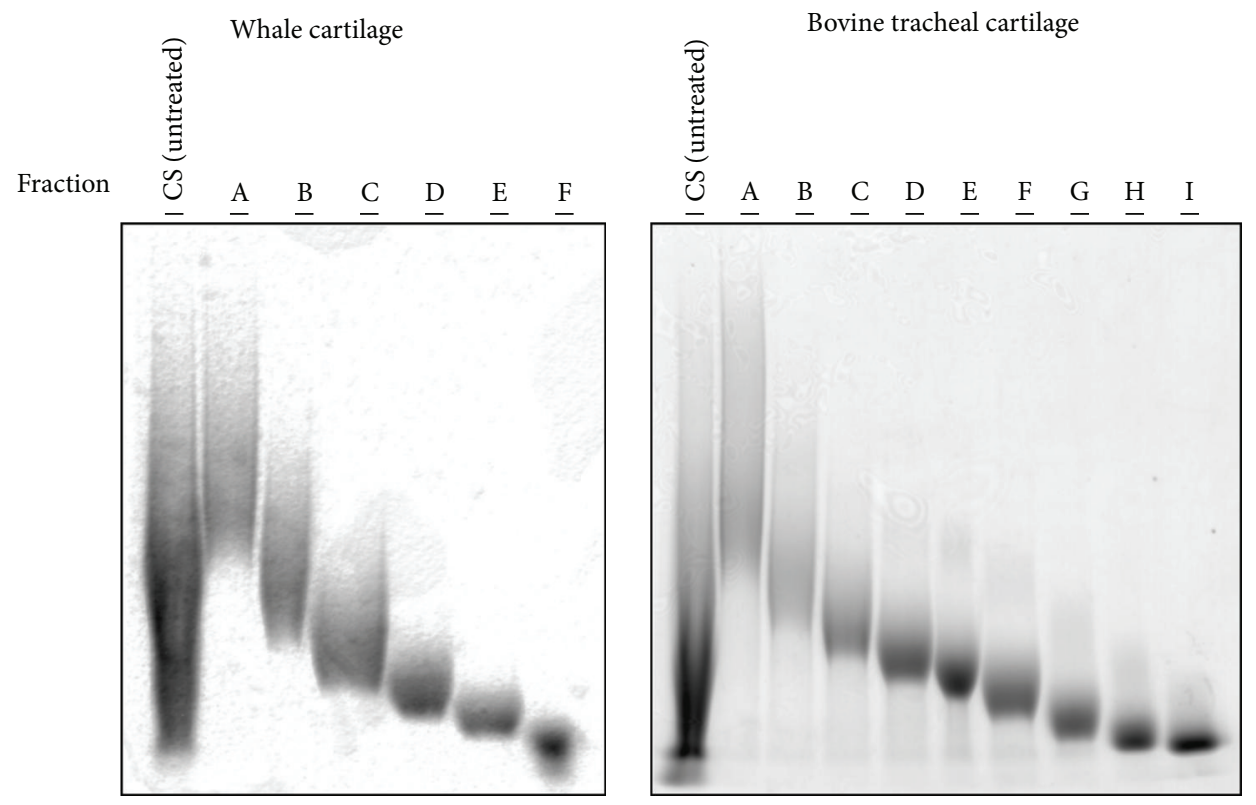

FIGURE 1: Gradient PAGE profiles of original and fractionated chondroitin sulfate.

2.7. Sensitization Protocol. The mice $(n=5)$ were intraperitoneally sensitized with $20 \mathrm{mg}$ of OVA and $2 \mathrm{mg}$ of an aluminium hydroxide hydrate $\left[\mathrm{Al}(\mathrm{OH})_{3} \cdot x \mathrm{H}_{2} \mathrm{O}\right]$ gel suspension (LSL Co. Ltd., Japan) in a total volume of $400 \mu \mathrm{L}$ of saline. On 14th day after the first sensitization, the mice were boosted using the same doses of the antigen. On the following day, the mice were sacrificed and their spleens were harvested.

2.8. Preparation and Stimulation of Murine Splenocytes In Vitro. The spleens of mice were removed and cell suspensions were made by passing them through a sterile cell strainer (Becton Dikcinson, CA, USA). The cell suspensions were washed twice in RPMI 1640 medium supplemented with penicillin-streptomycin, $0.1 \mathrm{M}$ sodium pyruvate, $0.2 \mathrm{M} \mathrm{L-}$ glutamine, $0.05 \mathrm{mM}$ 2-mercaptoethanol, and FBS, counted by Trypan Blue exclusion staining and adjusted to $5 \times 10^{6}$ cells $/ \mathrm{mL}$. The cells were plated at $2 \mathrm{~mL} /$ well in a 24 -well cell culture cluster (Corning, NY, USA) and challenged with OVA at a final concentration of $100 \mu \mathrm{g} / \mathrm{mL}$. Furthermore, the samples (each at a final concentration of $0.5 \mu \mathrm{M}$ ) or saline in vitro was added to the 24 -well culture cluster at $37^{\circ} \mathrm{C}$ in triplicate in a $\mathrm{CO}_{2}$ incubator for $72 \mathrm{hrs}$. The supernatants were then harvested for cytokine production analysis after $72 \mathrm{hrs}$ of incubation.

2.9. Production of Cytokine In Vitro. The cytokines examined in this study were IFN- $\gamma$, IL-2, IL-5, and IL-10. The amount of several cytokines in the culture medium after incubation was measured using an ELISA kit (OptEIA TM set, Pharmingen, San Diego, CA, USA). The principle of all ELISA kits was to employ the quantitative sandwich enzyme immunoassay technique. The absorbance was measured at $450 \mathrm{~nm}$ with UVVIS microplate reader (SUNRISE THERMO, TECAN Japan Co. Ltd., Tokyo).

\section{Results}

3.1. Fractionation of CS. CS has several isomers which have different degrees of sulfonation and binding sites of sulfonate groups [24-26]. Generally, intact CS chains show various MW and a range of their MW is extremely wide from thousands to hundreds of thousands [2-4]. Based on this fact, we firstly fractionated commercially available CS by lowpressure gel chromatography to prepare CS within a strictly limited range of average MW. Two different types of CS samples were applied: one was derived from whale cartilage which is mainly composed of CS-A structure [GlcA ( $\beta 1-3)$ GalNAc4S], and the other was from bovine tracheal cartilage which is mainly composed of CS-A structure [GlcA ( $\beta 1$ 3) GalNAc4S] $[27,28]$. Sephadex G100 Superfine, by which the available fractionation range is from 1 to $100 \mathrm{kDa}$, was employed for preparation of CS as the average MW of CS from whale cartilage and bovine tracheal cartilage was $21 \mathrm{kDa}$ and $15 \mathrm{kDa}$, respectively. The structure of each fractionated CS was confirmed by the HPLC for disaccharide analysis and ${ }^{1} \mathrm{H}$ NMR (data not shown). The extent of fractionation of CS was confirmed by applying gradient polyacrylamide gel electrophoresis (PAGE), and we confirmed that we could obtain CS with strictly limited range of MW (Figure 1 and Table 1). Six fractionated CSs from whale cartilage, of which original average $\mathrm{MW}$ was $21 \mathrm{kDa}$, were estimated from 7 to $29 \mathrm{kDa}$. As for CS from bovine tracheal cartilage, the range of MW was from 6 to $33 \mathrm{kDa}$.

3.2. Disaccharide Analysis for Fractionated CS. Since it has already been reported that the difference of sulfonation pattern/degree has an impact on a bioactivity of CS, we analyzed the disaccharide composition of the fractionated CS chains. To be concrete, unfractionated and fractionated CSs were degraded by the action of chondroitin lyases and then 
TABLE 1: Molecular weight of fractionated chondroitin sulfate.

\begin{tabular}{lcc}
\hline \multirow{2}{*}{ Fraction } & \multicolumn{2}{c}{ Mean molecular weight $(\mathrm{kDa})$} \\
& Whale cartilage & Bovine tracheal cartilage \\
\hline CS (untreated) & 21 & 15 \\
A & 29 & 33 \\
B & 21 & 26 \\
C & 15 & 21 \\
D & 12 & 17 \\
E & 9 & 15 \\
F & 7 & 13 \\
G & - & 9 \\
H & - & 7 \\
I & - & 6 \\
\hline
\end{tabular}

the compositions of these disaccharides were determined by the reverse-phase ion-pair chromatography with the postcolumn fluorogenic reactions. As a result, it was revealed that the contents of major disaccharide units, which are $\Delta \mathrm{Di}-4 \mathrm{~S}$ and $\Delta \mathrm{Di}-6 \mathrm{~S}$, were quite similar as that of the original CS after fractionation (Table 2). The contents of $\Delta \mathrm{Di}-4 \mathrm{~S}$ were three and two times higher than those of $\Delta \mathrm{Di}-6 \mathrm{~S}$ in whale cartilage and bovine tracheal cartilage, respectively. In order to compare the immunoreactivity of both CS from whale and bovine cartilage, 7,15 , and $21 \mathrm{kDa}$ fractionated CS were used for further investigation.

3.3. Binding of CS to L-Selectin. To investigate the binding affinity between CS and L-selectin, and the effect of MW of CS on the binding affinity with L-selectin, we analyzed the binding affinity between CS and L-selectin by surface plasmon resonance (SPR) measurement employed with BIAcore, which is able to detect a biomolecular interaction without labels and analyzes an affinity and kinetics parameters quantitatively in real time. Diluted commercially available recombinant murine L-selectin in $10 \mathrm{mM}$ acetic buffer $(\mathrm{pH}$ 4.0) was immobilized to a CM5 sensor chip by the aminocoupling reaction and $11.7 \mathrm{ng} / \mathrm{mm}^{2}$ of the L-selectin could be immobilized. Subsequently, the interaction between the fractionated CS and L-selectin was investigated. Figure 2 shows both untreated and fractionated CS could interact with L-selectin through dose dependence. As compared with the association and dissociation phases of sensorgrams of the fractionated CS from bovine tracheal cartilage with Lselectin, those of CS from whale cartilage were steeper; that is, the interaction with CS from whale cartilage with L-selectin is tighter. Kinetic parameters such as association constant $\left(K_{A}\right)$, dissociation constant $\left(K_{D}\right)$, association rate constant $\left(k_{a}\right)$, and dissociation rate constant $\left(k_{d}\right)$ were calculated as the Langmuir formula. Evaluation of the kinetic parameters (Table 3) indicated that $K_{D}$ of the fractionated CS with $21 \mathrm{kDa}$ in both CS was the smallest and there was the tendency of $K_{D}$ to increase in a molecular weight-dependent manner. Although untreated CS and fractionated CS had the same average MW, $K_{D}$ of fractionated CS was smaller in comparison to that of untreated CS. It suggests that CS with narrower molecular distribution has a higher affinity with L-selectin compared to CS with a wide range of MW. Furthermore, there was considerable difference for untreated CS from whale cartilage and bovine tracheal cartilage in the affinity with L-selectin, even though the disaccharide compositions of these CS samples showed no significant difference (Tables 2 and 3 ). These results suggest that not only sulfonation pattern including disaccharide sequence but also MW of CS may affect the affinity with L-selectin.

The many studies on bioactivity of CS have been focused on its sulfonation to date. However, our findings suggest that MW of CS could have effect on such a bioactivity of CS as well as sulfonation pattern of CS.

3.4. Effects of Fractionated CS on Cytokine Production of Mice Splenocytes. To examine the effects of CS with various MWs on cytokine production, splenocytes from OVA-sensitized $\mathrm{BALB} / \mathrm{c}$ mice were challenged with OVA in the presence and absence of untreated and fractionated CS, and the cytokine levels in the medium of the cultured cells were measured. As shown in Figure 3(a), the levels of IFN- $\gamma$, Th1-type cytokine, produced by the splenocytes cultured with fractionated CS from whale cartilage were significantly higher than the levels produced by splenocytes cultured with OVA alone and untreated CS. The production of IFN- $\gamma$ was the most strongly induced by being cultured with fractionated CS with $21 \mathrm{kDa}$. As for fractionated CS from bovine tracheal cartilage, it has a tendency to increase the level of IFN- $\gamma$ in MW dependent. These results coincided with the result of study on the interaction between CS and L-selectin. IL-2 also belongs to Th1-type cytokines but no significant effect on IL- 2 production like an IFN- $\gamma$ production was observed in both CS from whale cartilage and bovine tracheal cartilage (data not shown). In contrast to Thl cytokines, as shown in Figure 3(b), the levels of Th2 cytokine, IL-5 produced by the splenocytes cultured with fractionated CS from bovine tracheal cartilage were significantly lower than the levels produced by splenocytes cultured with OVA alone. There was a weak tendency to decrease the level of IL-5 production in CS from whale cartilage-treated splenocytes. It seems that fractionated CS has stronger effect on the inhibition of IL-5 production compared to untreated CS. As for the production of IL-10 which is also Th2-type cytokine, decreasing in its production level produced by the splenocytes cultured with fractionated CS was observed (data not shown).

\section{Discussion}

Selectin is one of cell surface receptors which is engaged in the adhesion between white blood cells and vascular endothelial cells, and it is involved with penetration of white blood cells into extravascular as an adhesion molecule [26]. Presently, three types of selectins, that is, E-, P-, and L-selectin, are reported. E- and P-selectins are expressed in vascular endothelial cell surface and platelets, respectively, and Lselectin is expressed on cell membranes of monocytes, neutrophils, part of natural killer cells, and T and B lymphocytes. Selectins are known as a type I membrane glycoprotein with a C-type lectin domain in its $N$-terminal domain $[29,30]$. 
TABLE 2: Disaccharide compositions of unfractionated and fractionated chondroitin sulfate samples from whale and bovine cartilage.

\begin{tabular}{|c|c|c|c|c|c|c|c|}
\hline Fraction & $\Delta \mathrm{Di}-0 \mathrm{~S}$ & $\Delta \mathrm{Di}-4 \mathrm{~S}$ & $\Delta \mathrm{Di}-6 \mathrm{~S}$ & $\Delta \mathrm{Di}-\mathrm{diS}_{\mathrm{E}}$ & $\Delta$ Di-diS $S_{B}$ & $\Delta$ Di-diS ${ }_{D}$ & $\Delta$ Di-triS \\
\hline \multicolumn{8}{|c|}{ Whale cartilage } \\
\hline CS (untreated) & 1.2 & 76.8 & 20.9 & 0.3 & N.D. & 0.7 & Trace \\
\hline A & 1.2 & 75.7 & 22.8 & 0.1 & N.D. & 0.2 & Trace \\
\hline $\mathrm{B}$ & 1.3 & 75.4 & 22.7 & 0.2 & N.D. & 0.4 & Trace \\
\hline $\mathrm{C}$ & 1.5 & 75.7 & 22.4 & 0.1 & N.D. & 0.3 & Trace \\
\hline $\mathrm{D}$ & 1.5 & 76.3 & 21.9 & 0.1 & N.D. & 0.2 & Trace \\
\hline $\mathrm{E}$ & 1.5 & 76.7 & 21.0 & 0.2 & N.D. & 0.5 & Trace \\
\hline $\mathrm{F}$ & 3.4 & 76.0 & 20.4 & 0.1 & N.D. & 0.1 & Trace \\
\hline \multicolumn{8}{|c|}{ Bovine tracheal cartilage } \\
\hline CS (untreated) & 8.1 & 56.5 & 33.8 & 0.6 & N.D. & 1.0 & Trace \\
\hline A & 6.7 & 61.3 & 30.9 & 0.5 & N.D. & 0.7 & Trace \\
\hline B & 7.5 & 62.3 & 29.0 & 0.5 & N.D. & 0.7 & Trace \\
\hline $\mathrm{C}$ & 7.3 & 61.7 & 29.7 & 0.5 & N.D. & 0.8 & Trace \\
\hline $\mathrm{D}$ & 6.6 & 59.1 & 33.1 & 0.4 & N.D. & 0.7 & Trace \\
\hline $\mathrm{E}$ & 6.4 & 55.7 & 36.9 & 0.3 & N.D. & 0.6 & Trace \\
\hline $\mathrm{F}$ & 6.7 & 52.1 & 40.3 & 0.3 & N.D. & 0.6 & Trace \\
\hline G & 5.4 & 50.0 & 43.4 & 0.4 & N.D. & 0.8 & Trace \\
\hline $\mathrm{H}$ & 8.6 & 50.1 & 40.2 & 0.3 & N.D. & 0.9 & Trace \\
\hline I & 8.2 & 48.7 & 41.6 & 0.4 & N.D. & 1.0 & Trace \\
\hline
\end{tabular}

Disaccharide compositions (\%) of untreated and fractionated CS were determined by HPLC on an amino-bound silica column after chondroitinase $\mathrm{ABC}$ digestion as described previously. $\Delta \mathrm{Di}-0 \mathrm{~S}, \Delta^{4,5} \mathrm{HexA}(\alpha \mathrm{l}-3)$ GalNAc; $\Delta \mathrm{Di}-4 \mathrm{~S}, \Delta^{4,5} \mathrm{HexA}(\alpha \mathrm{l}-3)$ GalNAc$\left(4-\mathrm{O}-\right.$ sulfate); $\Delta \mathrm{Di}-6 \mathrm{~S}, \Delta^{4,5} \mathrm{HexA}(\alpha \mathrm{l}-3) \mathrm{GalNAc}(6-$ O-sulfate); $\Delta$ Di-diSE, $\Delta^{4,5} \mathrm{HexA}(\alpha \mathrm{l}-3) \mathrm{GalNAc}\left(4,6\right.$-O-disulfate); $\Delta \mathrm{Di}$-diSB, $\Delta^{4,5} \mathrm{HexA}\left(2\right.$-O-sulfate) $(\alpha \mathrm{l}-3) \mathrm{GalNAc}\left(4-\mathrm{O}\right.$-sulfate); $\Delta \mathrm{Di}$-diSD, $\Delta^{4,5} \mathrm{HexA}(2-\mathrm{O}$ sulfate)( $\alpha \mathrm{l}$-3)GalNAc(4-O-sulfate); $\Delta \mathrm{Di}$-tirS, $\Delta^{4,5} \mathrm{HexA}(2$-O-sulfate)( $\alpha \mathrm{l}-3) \mathrm{GalNAc}(4,6$-O-disulfate); N.D.: not determined.

TABLE 3: Kinetic parameters for the interaction of fractionated chondroitin sulfate with immobilized L-selectin.

\begin{tabular}{|c|c|c|c|c|c|}
\hline & Fraction & $k_{a}\left(\mathrm{M}^{-1} \mathrm{~s}^{-1}\right)$ & $k_{d}\left(\mathrm{~s}^{-1}\right)$ & $K_{A}\left(\mathrm{M}^{-1}\right)$ & $K_{D}(\mu \mathrm{M})$ \\
\hline \multirow{4}{*}{ Whale cartilage } & CS (untreated) & $6.16 \times 10^{2}$ & $7.52 \times 10^{-3}$ & $8.18 \times 10^{4}$ & 12.2 \\
\hline & $\mathrm{B}(21 \mathrm{kDa})$ & $7.58 \times 10^{3}$ & $2.27 \times 10^{-2}$ & $3.34 \times 10^{5}$ & 3.0 \\
\hline & $\mathrm{C}(15 \mathrm{kDa})$ & $2.31 \times 10^{3}$ & $2.05 \times 10^{-2}$ & $1.13 \times 10^{5}$ & 8.8 \\
\hline & $\mathrm{E}(9 \mathrm{kDa})$ & $6.05 \times 10^{2}$ & $3.42 \times 10^{-2}$ & $1.77 \times 10^{4}$ & 56.4 \\
\hline \multirow{4}{*}{ Bovine tracheal cartilage } & CS (untreated) & $3.32 \times 10^{2}$ & $1.30 \times 10^{-2}$ & $2.56 \times 10^{4}$ & 39.1 \\
\hline & $\mathrm{C}(21 \mathrm{kDa})$ & $7.97 \times 10^{2}$ & $3.48 \times 10^{-3}$ & $2.23 \times 10^{5}$ & 4.5 \\
\hline & $\mathrm{E}(15 \mathrm{kDa})$ & $1.22 \times 10^{2}$ & $2.30 \times 10^{-3}$ & $5.29 \times 10^{4}$ & 18.9 \\
\hline & $\mathrm{G}(9 \mathrm{kDa})$ & $4.52 \times 10^{2}$ & $2.37 \times 10^{-2}$ & $2.00 \times 10^{4}$ & 49.9 \\
\hline
\end{tabular}

The association rate constant $\left(k_{a}\right)$, dissociation $\left(k_{d}\right)$ rate constant, equilibrium association constant $\left(K_{A}\right)$ and equilibrium dissociation constant $\left(K_{D}\right)$ for the interaction of CS with immobilized L-selectin were determined by BIAcore. Standard errors of kinetic parameters obtained were within $15 \%$ by tripricate experiments.

The C-type lectin domain of L-selectin is known to interact with several glycan ligands directly. MAdCAM-1 [31], CD 34 [32], podocalyxin [33], and GlyCAM-1 [34] have been identified as L-selectin ligands which are expressed on cell surface of endothelial venule. Recently, it has been reported that penetration of white blood cell into an inflammatory tissue was inhibited by administration of anti-L-selectin antibody, and that penetration of white blood cell was suppressed significantly in L-selectin knock-out mouse $[35,36]$. Consequently, it is assumed that L-selectin and the ligand play a role in penetration of white blood cell to nonlymphoid tissue, but the ligand is still unknown. Kawashima et al. revealed that Lselectin binding substance except for Sialyl-Lewis X exists in white matter and distal tubule which are nonlymphoid tissue and versican, a large chondroitin/dermatan sulfate (CS/DS) proteoglycan, interacts through its CS/DS chains with L- and P-selectin and CD $44[15,16,18]$. And we have reported that CS impacts intracellular transcription system through contact with L-selectin in OVA-sensitized mouse [12].

It has been shown that CSPG and CS are involved in anti-inflammatory reaction [37-39]. We also reported for the immunochemical reactivities of CS on murine splenocytes sensitized with OVA in order to demonstrate that CS could be associated with immune system. And we revealed that CS affects the pattern of cytokine production, differentiation of lymphocyte subsets, and level of IFN- $\gamma$ mRNA in 

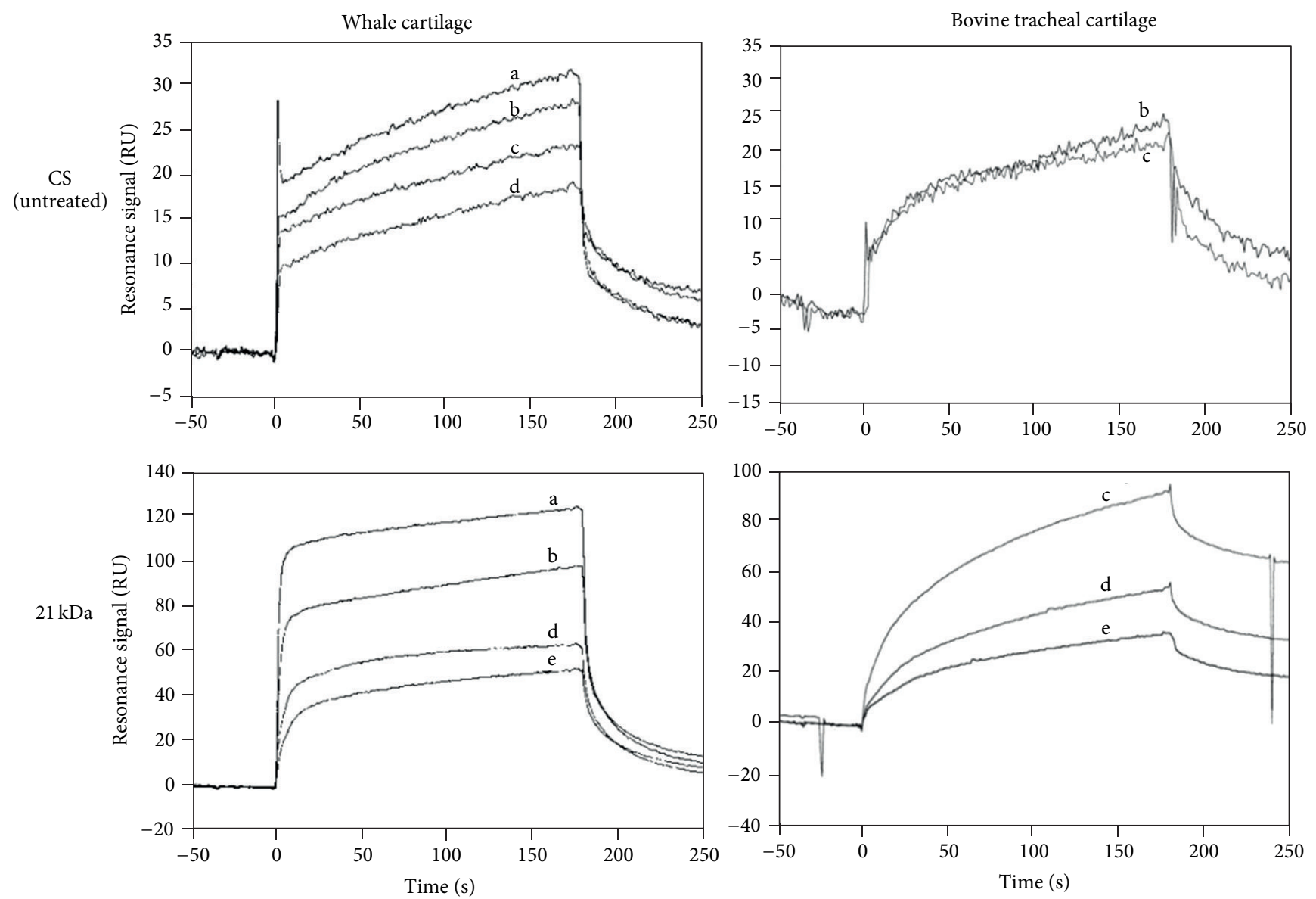

FIGURE 2: Sensorgrams of recording the interaction of fractionated chondroitin sulfate with immobilized L-selectin in the BIAcore. Various concentrations of original CS and fractionated CS (a, $50 \mu \mathrm{g} / \mathrm{mL} ; \mathrm{b}, 100 \mu \mathrm{g} / \mathrm{mL} ; \mathrm{c}, 250 \mu \mathrm{g} / \mathrm{mL} ; \mathrm{d}, 500 \mu \mathrm{g} / \mathrm{mL} ; \mathrm{e}, 1000 \mu \mathrm{g} / \mathrm{mL}) \mathrm{were}$ continuously injected over sensor chip surfaces coupled to L-selectin at a $20 \mu \mathrm{L} / \mathrm{min}$; after this, running buffer was injected and the response in resonance units was recorded as a function time.

the splenocytes of the mice immunized with OVA. Furthermore, it was shown that CS induced these reactions by interacting with L-selectin in sulfonation degree-dependent manner, and these findings suggest that CS could impact transcription system [12,13]. Additionally, Zhou and his group have reported on the immune modulation by the animal model of experimental autoimmune encephalomyelitis (EAE) using CS and its disaccharide. It was shown that CSA and disaccharide degradation of CSPG had an opposite effect on EAE [40]. Thus, it is suggested that CS has different immunochemical reactivity due to its structural variation. In this study, we focused on a variability of MW of CS in order to investigate the immunochemical reactivities of CS in detail and investigated the effect of CS with different MW on systemic immune systems.

\section{Conclusion}

In the past, many studies on the bioactivities of CS have been focused on the degree of its sulfonation patterns and they revealed that effects of CS on bioactivities differ with the degree and positions of sulfonation CS chains. However, we clarified here that the immunoreactivity of CS is affected by the MW, length of leaner polysaccharide chains, of CS. Furthermore, even though the MW of CS was similar, the effect on the production of IFN- $\gamma$ and IL- 5 by mouse splenocytes was more augmented by CS with a narrow range of MW compared to CS with a broad range of MW. Namely, it is suggested that the length of polysaccharide chains of CS has also the impact on the immunoreactivity.

\section{Conflict of Interests}

There is no ethical problem or conflict of interests with regard to this paper.

\section{Acknowledgments}

This work was supported in part by both Special Funds for Education and Research (Development of SPECT Probes for Pharmaceutical Innovation) from the Ministry of Education, Culture, Sports, Science, and Technology, Japan, and by 

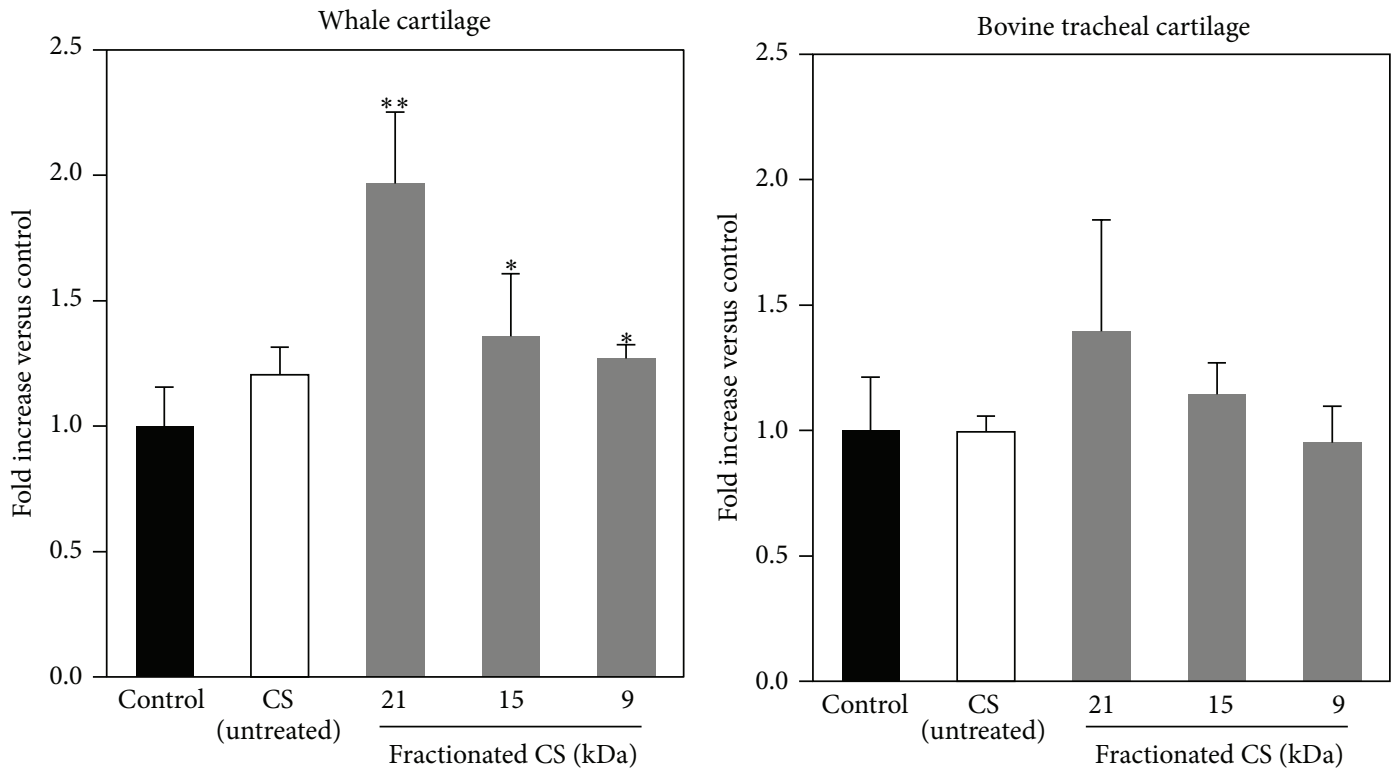

(a)
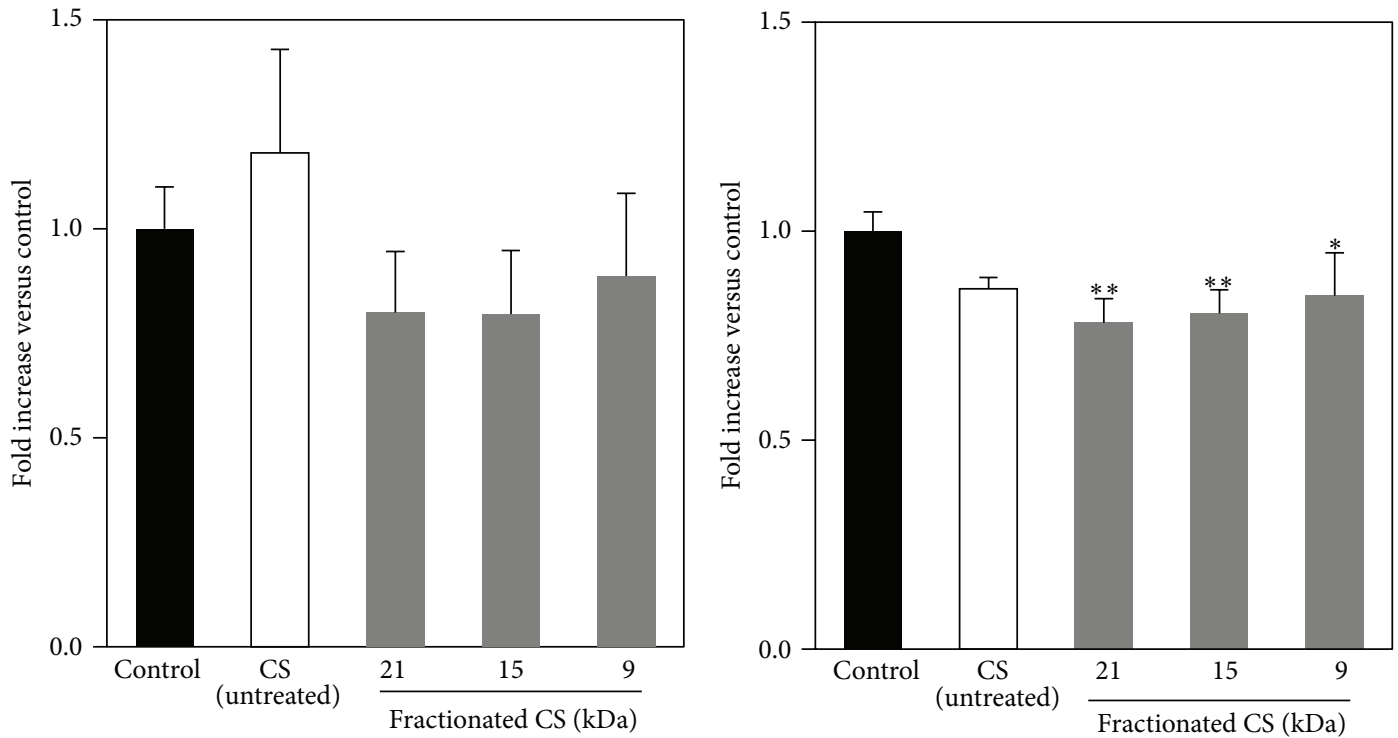

(b)

FIGURE 3: Effect of fractionated chondroitin sulfate on the cytokine productions of murine splenocytes in vitro. (a) IFN- $\gamma$ production. (b) IL-5 production. BALB/c mice $(n=5)$ were intraperitoneally injected on day 0 and day 14 with $20 \mu \mathrm{g}$ of OVA and $2 \mathrm{mg}$ of $\mathrm{Al}(\mathrm{OH})_{3}$ in a total volume of $400 \mu \mathrm{L}$. Splenocytes $\left(5.0 \times 10^{6}\right.$ cells $\left./ \mathrm{mL}\right)$ were collected on day 15 and were cocultured with OVA (final concentration $100 \mu \mathrm{g} / \mathrm{mL}$ ). The samples (each at a final concentration of $0.5 \mu \mathrm{M}$ ) or saline in vitro was added to the 24 -well culture cluster in triplicate at $37^{\circ} \mathrm{C}$ in a $\mathrm{CO}_{2}$ incubator for $48 \mathrm{hrs}$. The amounts of cytokines in the supernatant were measured by ELISA. ${ }^{*} P<0.05,{ }^{* *} P<0.01$ (significantly different from control value). Error bars represent means \pm S.D. for 6 wells.

Grants from the Ministry of Health, Labour, and Welfare of Japan and from the Japanese Health Sciences Foundation (KHB1212, TT).

\section{References}

[1] L. Roden, "Structure and metabolism of connective tissue proteoglycans," in The Biochemistry of Glycoproteins and Proteoglycans, pp. 267-371, Plenum Press, New York, NY, USA, 1980.
[2] K. Kimata, M. Okayama, A. Oohira, and S. Suzuki, "Cytodifferentiation and proteoglycan biosynthesis," Molecular and Cellular Biochemistry, vol. 1, no. 2, pp. 211-228, 1973.

[3] T. Toida, H. Toyoda, and T. Imanari, "High-resolution proton nuclear magnetic resonance studies on chondroitin sulfates," Analytical Sciences, vol. 9, pp. 53-58, 1993.

[4] J. E. Scott, "Structure and function in extracellular matrices depend on interactions between anionic glycosaminoglycans," Pathologie Biologie, vol. 49, no. 4, pp. 284-289, 2001. 
[5] K. Sugahara, T. Mikami, T. Uyama, S. Mizuguchi, K. Nomura, and H. Kitagawa, "Recent advances in the structural biology of chondroitin sulfate and dermatan sulfate," Current Opinion in Structural Biology, vol. 13, no. 5, pp. 612-620, 2003.

[6] A. Salustri, A. Camaioni, M. di Giacomo, C. Fulop, and V. C. Hascall, "Hyaluronan and proteoglycans in ovarian follicles," Human Reproduction Update, vol. 5, no. 4, pp. 293-301, 1999.

[7] M. Yoneda, S. Shimizu, Y. Nishi, M. Yamagata, S. Suzuki, and K. Kimata, "Hyaluronic acid-dependent change in the extracellular matrix of mouse dermal fibroblasts that is conducive to cell proliferation," Journal of Cell Science, vol. 90, no. 2, pp. 275-286, 1988.

[8] G. S. Kelly, "The role of glucosamine sulfate and chondroitin sulfates in the treatment of degenerative joint disease," Alternative Medicine Review, vol. 3, no. 1, pp. 27-39, 1998.

[9] T. Omata, Y. Segawa, Y. Itokazu, N. Inoue, and Y. Tanaka, "Effects of chondroitin sulfate-C on bradykinin-induced proteoglycan depletion in rats," Arzneimittel-Forschung/Drug Research, vol. 49, no. 7, pp. 577-581, 1999.

[10] J. Beren, S. L. Hill, M. Diener-West, and N. R. Rose, "Effect of pre-loading oral glucosamine $\mathrm{HCI} /$ chondroitin sulfate/manganese ascorbate combination on expierimental arthritis in rats," Proceedings of the Society for Experimental Biology and Medicine, vol. 226, no. 2, pp. 144-151, 2001.

[11] G. Rovetta, "Galactosaminoglycuronoglycan sulfate (Matrix) in therapy of tibiofibular osteoarthritis of the knee," Drugs under Experimental and Clinical Research, vol. 17, no. 1, pp. 53-57, 1991.

[12] S. Sakai, H. Akiyama, N. Harikai et al., "Effect of chondroitin sulfate on murine splenocytes sensitized with ovalbumin," Immunology Letters, vol. 84, no. 3, pp. 211-216, 2002.

[13] H. Akiyama, S. Sakai, R. J. Linhardt, Y. Goda, T. Toida, and T. Maitani, "Chondroitin sulphate structure affects its immunological activities on murine splenocytes sensitized with ovalbumin," Biochemical Journal, vol. 382, no. 1, pp. 269-278, 2004.

[14] S. Haylock-Jacobs, M.B. Keough, L. Lau, and V. W. Yon, "Chondroitin sulphate proteoglycans: extracellular matrix proteins that regulate immunity of the central nervous system," Autoimmunity Reviews, vol. 10, no. 12, pp. 766-772, 2011.

[15] H. Kawashima, Y. F. Li, N. Watanabe, J. Hirose, M. Hirose, and M. Miyasaka, "Identification and characterization of ligands for L-selectin in the kidney. I. Versican, a large chondroitin sulfate proteoglycan, is a ligand for L-selectin," International Immunology, vol. 11, no. 3, pp. 393-405, 1999.

[16] H. Kawashima, M. Hirose, J. Hirose, D. Nagakubo, A. H. K. Plaas, and M. Miyasaka, "Binding of a large chondroitin sulfate/dermatan sulfate proteoglycan, versican, to L-selectin, Pselectin, and CD44," Journal of Biological Chemistry, vol. 275, no. 45, pp. 35448-35456, 2000.

[17] H. Kawashima, K. Atarashi, M. Hirose et al., "Oversulfated chondroitin/dermatan sulfates containing GlcA $\beta 1 / \operatorname{IdoA} \alpha 1$ 3GalNAc(4,6-O-disulfate) interact with $\mathrm{L}$ - and P-selectin and chemokines," Journal of Biological Chemistry, vol. 277, no. 15, pp. 12921-12930, 2002.

[18] J. Hirose, H. Kawashima, O. Yoshie, K. Tashiro, and M. Miyasaka, "Versican interacts with chemokines and modulates cellular responses," Journal of Biological Chemistry, vol. 276, no. 7, pp. 5228-5234, 2001.

[19] A. K. Abbas, K. M. Murphy, and A. Sher, "Functional diversity of helper T lymphocytes," Nature, vol. 383, no. 6603, pp. 787-793, 1996.
[20] K. M. Murphy and S. L. Reiner, "The lineage decisions of helper T cells," Nature Reviews Immunology, vol. 2, no. 12, pp. 933-944, 2002.

[21] T. Toida, K. Sato, N. Sakamoto, S. Sakai, S. Hosoyama, and R. J. Linhardt, "Solvolytic depolymerization of chondroitin and dermatan sulfates," Carbohydrate Research, vol. 344, no. 7, pp. 888-893, 2009.

[22] H. Toyoda, K. Shinomiya, S. Yamanashi, I. Koshiishi, and T. Imanari, "Microdetermination of unsaturated disaccharide's produced from chondroitinsulfates in rabbit plasma by highperformance liquid chromatography with fluorometric detection," Analytical Sciences, vol. 4, pp. 381-384, 1988.

[23] H. Toyoda, K. Motoki, M. Tanikawa, K. Shinomiya, H. Akiyama, and T. Imanari, "Determination of human urinary hyaluronic acid, chondroitin sulphate and dermatan sulphate as their unsaturated disaccharides by high-performance liquid chromatography," Journal of Chromatography, vol. 565, no. 1-2, pp. 141-148, 1991.

[24] J. A. Santos, B. Mulloy, and P. A. S. Mourao, "Structural diversity among sulfated $\alpha$-L-galactans from ascidians (tunicates) studies on the species Ciona intestinalis and Herdmania monus," The European Journal of Biochemistry, vol. 204, no. 2, pp. 669-677, 1992.

[25] A. P. Alves, B. Mulloy, J. A. Diniz, and P. A. S. Mourão, "Sulfated polysaccharides from the egg jelly layer are species-specific inducers of acrosomal reaction in sperms of sea urchins," Journal of Biological Chemistry, vol. 272, no. 11, pp. 6965-6971, 1997.

[26] W. R. L. Farias, A. P. Valente, M. S. Pereira, and P. A. S. Mourão, "Structure and anticoagulant activity of sulfated galactans. Isolation of a unique sulfated galactan from the red algae Botryocladia occidentalis and comparison of its anticoagulant action with that of sulfated galactans from invertebrates," Journal of Biological Chemistry, vol. 275, no. 38, pp. 2929929307, 2000.

[27] Y. M. Michelacci and C. P. Dietrich, "Structure of chondroitin sulphate from whale cartilage: distribution of 6- and 4sulphated oligosaccharides in the polymer chains," International Journal of Biological Macromolecules, vol. 8, no. 2, pp. 108-113, 1986.

[28] D. Vestweber and J. E. Blanks, "Mechanisms that regulate the function of the selectins and their ligands," Physiological Reviews, vol. 79, no. 1, pp. 181-213, 1999.

[29] M. P. Bevilacqua and R. M. Nelson, "Selectins," Journal of Clinical Investigation, vol. 91, no. 2, pp. 379-387, 1993.

[30] S. D. Rosen and C. R. Bertozzi, "The selectins and their ligands," Current Opinion in Cell Biology, vol. 6, no. 5, pp. 663-673, 1994.

[31] E. L. Berg, L. M. McEvoy, C. Berlin, R. F. Bargatze, and E. C. Butcher, "L-selectin-mediated lymphocyte rolling on MAdCAM-1," Nature, vol. 366, no. 6456, pp. 695-698, 1993.

[32] S. Baumhueter, M. S. Singer, W. Henzel et al., "Binding of Lselectin to the vascular sialomucin CD34," Science, vol. 262, no. 5132, pp. 436-438, 1993.

[33] C. Sassetti, K. Tangemann, M. S. Singer, D. B. Kershaw, and S. D. Rosen, "Identification of Podocalyxin-like protein as a high endothelial venule ligand for L-selectin: parallels to CD34," Journal of Experimental Medicine, vol. 187, no. 12, pp. 1965-1975, 1998.

[34] Y. Imai, L. A. Lasky, and S. D. Rosen, "Sulphation requirement for GlyCAM-1, an endothelial ligand for L-selectin," Nature, vol. 361, no. 6412, pp. 555-557, 1993. 
[35] M. L. Arbonés, D. C. Ord, K. Ley et al., "Lymphocyte homing and leukocyte rolling and migration are impaired in L-selectindeficient mice," Immunity, vol. 1, no. 4, pp. 247-260, 1994.

[36] T. R. Mosmann, H. Cherwinski, M. W. Bond, M. A. Giedlin, and R. L. Coffman, "Two types of murine helper T cell clone. I. Definition according to profiles of lymphokine activities and secreted proteins," Journal of Immunology, vol. 136, no. 7, pp. 2348-2357, 1986.

[37] F. Petersen, L. Bock, H. D. Flad, and E. Brandt, "A chondroitin sulfate proteoglycan on human neutrophils specifically binds platelet factor 4 and is involved in cell activation," Journal of Immunology, vol. 161, no. 8, pp. 4347-4355, 1998.

[38] P. Morreale, R. Manopulo, M. Galati, L. Boccanera, G. Saponati, and L. Bocchi, "Comparison of the antiinflammatory efficacy of chondroitin sulfate and diclofenac sodium in patients with knee osteoarthritis," Journal of Rheumatology, vol. 23, no. 8, pp. 13851391, 1996.

[39] F. Ronca, L. Palmieri, P. Panicucci, and G. Ronca, "Antiinflammatory activity of chondroitin sulfate," Osteoarthritis and Cartilage, vol. 6, pp. 14-21, 1998.

[40] J. Zhou, P. Nagarkatti, Y. Zhong, and M. Nagarkatti, "Immune modulation by chondroitin sulfate and its degraded disaccharide product in the development of an experimental model of multiple sclerosis," Journal of Neuroimmunology, vol. 223, no. 12, pp. 55-64, 2010. 

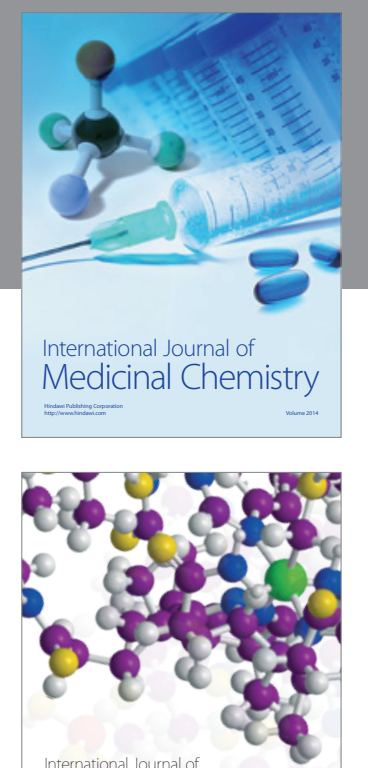

\section{Carbohydrate} Chemistry

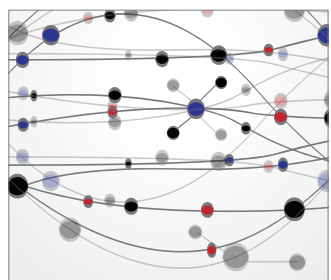

The Scientific World Journal
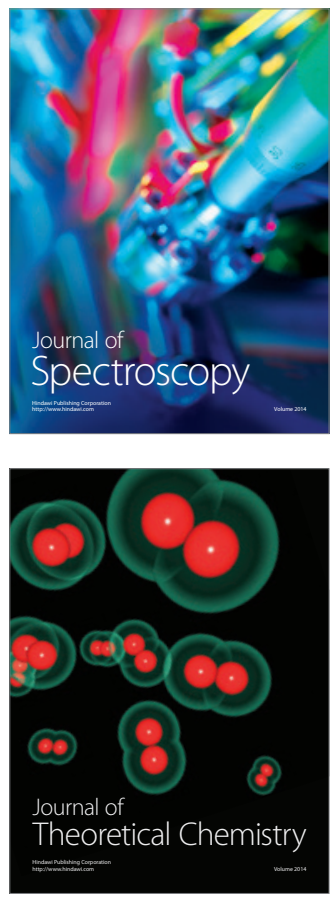
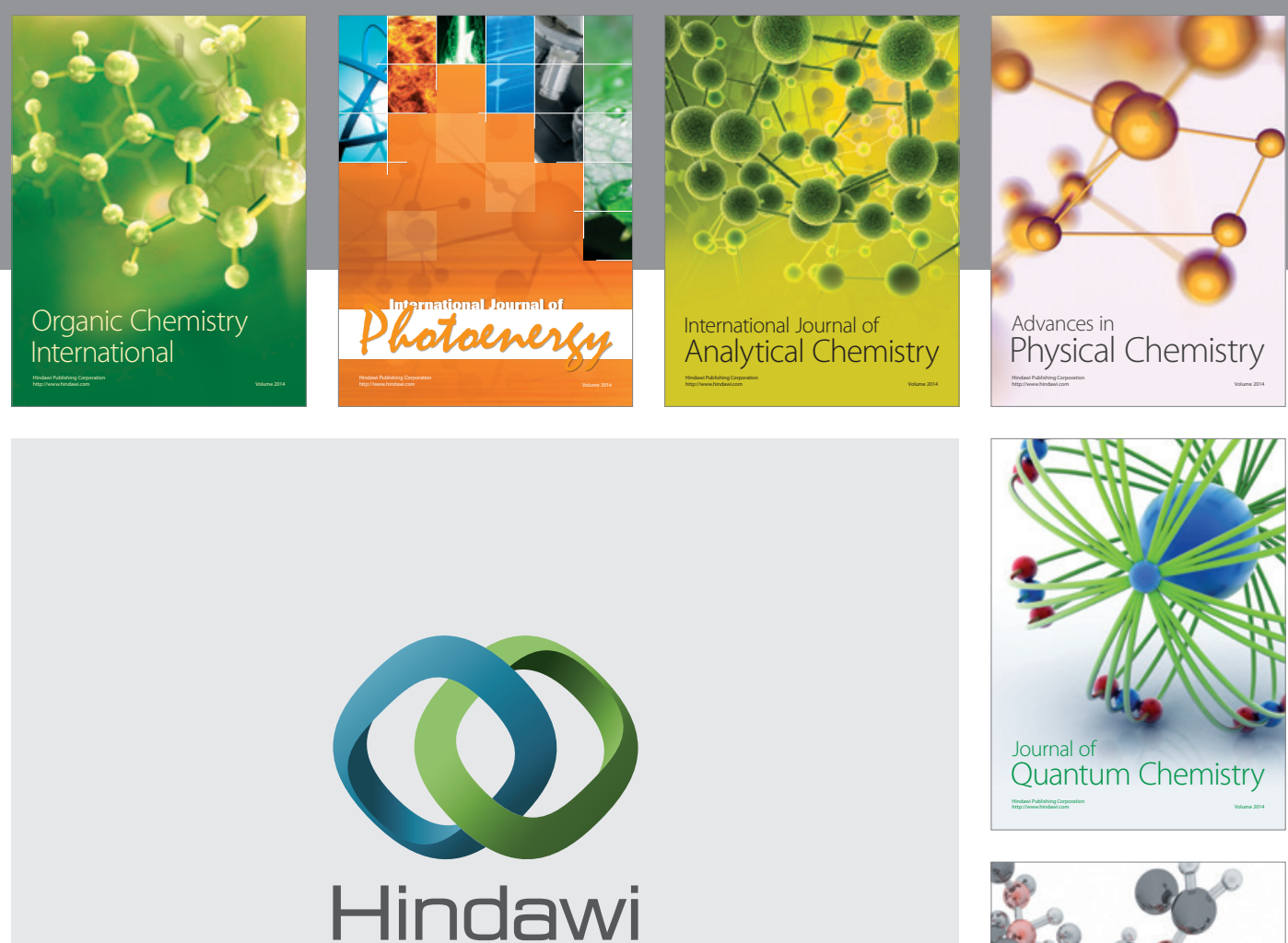

Submit your manuscripts at

http://www.hindawi.com

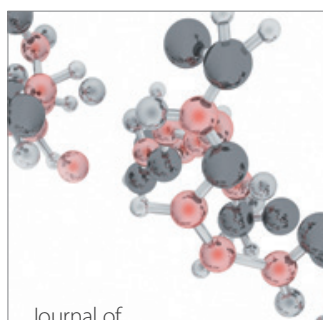

Analytical Methods

in Chemistry

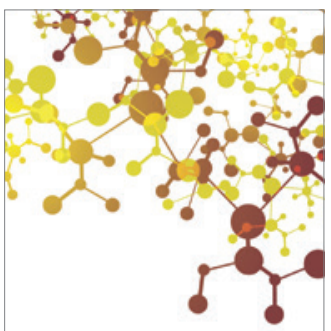

Journal of

Applied Chemistry

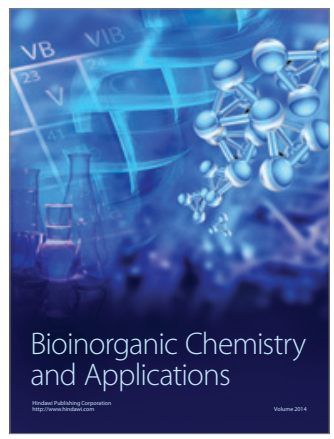

Inorganic Chemistry
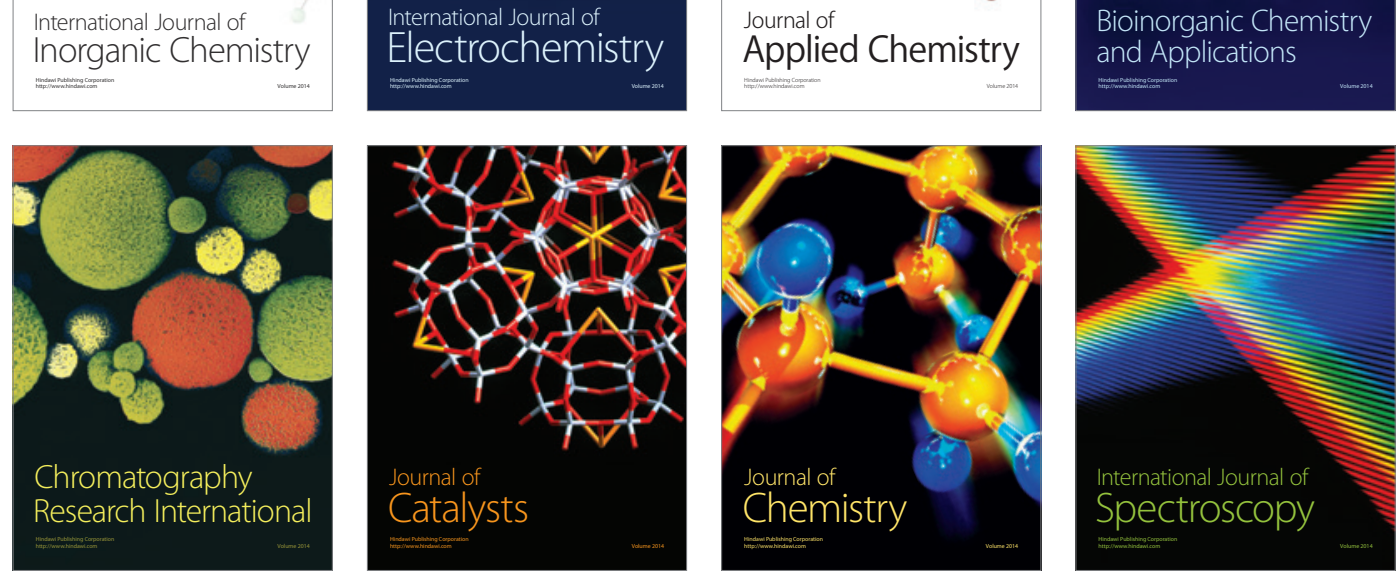